Check for updates

Cite this: Chem. Sci., 2017, 8, 8285

6th September 201

Accepted 14th October 2017

DOI: $10.1039 / \mathrm{c} 7 \mathrm{sc} 03903 \mathrm{~d}$

rsc.li/chemical-science

\section{Bioinspired synthesis of pentacyclic onocerane triterpenoids $\uparrow$}

\author{
Florian Bartels, (D) a Young J. Hong, ${ }^{b}$ Daijiro Ueda, (DD c Manuela Weber, (DD ${ }^{a}$ \\ Tsutomu Sato, (DD ${ }^{* c}$ Dean J. Tantillo (D) ${ }^{* b}$ and Mathias Christmann (D) *a
}

The first chemical synthesis of pentacyclic onocerane triterpenoids has been achieved. A putative biomimetic tricyclization cascade is employed to forge a fused decalin-/oxepane ring system. The synthetic route proceeds to $(+)$-cupacinoxepin in seven steps and to $(+)$-onoceranoxide in eight steps in the longest linear sequence, when starting from geranyl chloride and (+)-sclareolide. The bioinspired epoxypolyene cyclization is supported by computational and enzymatic studies.
Triterpenoids constitute an important family of diverse natural products with unique biological activities. ${ }^{1}$ Their structural complexity is generated by cyclase enzymes that convert simple acyclic isoprenoid precursors into polycyclic molecules. ${ }^{2,3}$ For example, onocerane triterpenes were shown to be biosynthesized from squalene (1) or its oxidized derivatives $(2,3)$ by cyclizations initiated at both termini. ${ }^{4}$ The intermediates and products can be distinguished by their oxidation level (OL), (carbo-)cyclization level (CL), and the hydration level (HL), i.e. the number of incorporated water molecules. Following core assembly, functional group modifications (FGMs) or $\mathrm{C}-\mathrm{H}$ oxidations $^{5}$ may occur (Scheme 1). In a bioassay-guided screening for anti-malarial compounds, Schuehly and coworkers reported the isolation of a novel triterpenoid from the bark of Cupania cinerea. ${ }^{6}$ Cupacinoxepin (4) showed moderate activity against the Plasmodium falciparum K1 strain $(8.7 \mu \mathrm{M})$ and features a novel fused pentacyclic onocerane scaffold composed of three six-membered carbocycles and two oxepanes. Although data from a single crystal suitable for X-ray crystallography was obtained, the absolute configuration could not be determined. ${ }^{6}$ Previous synthetic work on the onceranes $^{7-10}$ was focused on the tetracyclic $C_{2}$-symmetrical congeners onocerandiol $(5)^{11-14}$ and $\alpha$-onocerin $(6) .^{15-22}$ The biosynthesis of onoceranoxide (7) ${ }^{23}$ and $\alpha$-onocerin (6) via $\mathbf{8}^{\mathbf{2 4 , 2 5}}$

${ }^{a}$ Institute of Chemistry and Biochemistry, Freie Universität Berlin, Takustraße 3, 14195 Berlin, Germany. E-mail: mathias.christmann@fu-berlin.de

${ }^{b}$ Department of Chemistry, University of California-Davis, Davis, California 95616, USA.E-mail: djtantillo@ucdavis.edu

${ }^{c}$ Department of Applied Biological Chemistry, Graduate School of Science and Technology, Niigata University, Ikarashi 2-8050, Nishi-ku, Niigata 950-2181, Japan. E-mail: satot@agr.niigata-u.ac.jp

$\uparrow$ Electronic supplementary information (ESI) available: Detailed experimental procedures, spectral data, DFT calculation, X-ray crystallographic data for 4 (CIF), 13 (CIF), 10 (CIF), 22 (CIF). CCDC 1529115-1529118. For ESI and crystallographic data in CIF or other electronic format see DOI: 10.1039/c7sc03903d was hypothesized to proceed via cyclization of squalene and diepoxysqualene, respectively (Scheme 1). This process was elegantly mimicked by Corey's double allylsilane epoxypolyene cyclization. ${ }^{16}$ However, the highly substituted oxepane in cupacinoxepin (4) and onoceranoxide $(7)^{26,27}$ required a novel synthetic strategy.

Chemical synthesis of ditertiary ethers is a daunting task. ${ }^{28-38}$ Unfortunately, the seemingly obvious approach to form the oxepane from two tertiary alcohols is outpaced by competing cationic pathways. ${ }^{13,14}$ Inspired by the cyclization of squalene to 7 via 9 catalyzed by Bacillus megaterium tetraprenyl- $\beta$-curcumene cyclase (BmeTC), ${ }^{23}$ we identified myrrhanol C $(\mathbf{1 1})^{39}$ or epoxy dienol 12 as potential precursors for the synthesis of $\mathbf{1 0 .}$ While the actual biosynthetic pathway is unknown, the realization of an epoxydiene tricyclization appeared more feasible in a laboratory setting. Finally, oxidation of the secondary alcohol 10 to cupacinoxepin (4) (via the intermediacy of a ketone) completes the putative biosynthesis. Only a few examples of polyene cyclizations ${ }^{\mathbf{4 0 - 4 5}}$ using tertiary alcohols as nucleophiles are known, ${ }^{46-48}$ and to the best of our knowledge polyene tricyclizations using tertiary alcohols to form oxepanes have only been achieved enzymatically so far..$^{23,49}$ In order to probe this key cyclization $(\mathbf{1 2} \rightarrow \mathbf{1 0})$ in the laboratory, we selected epoxy dienol 12 as our retrosynthetic target (Scheme 2).

We envisioned the cyclization precursor 12 to be generated in a $B$-alkyl Suzuki-Miyaura coupling between an alkylborane derived from 13 and vinyl iodide 14. ${ }^{50}$ The two fragments were traced back to the readily available starting materials (+)-sclareolide (15) and geranyl chloride (16), respectively. ${ }^{51-53}$

The synthesis of fragment $13^{54}$ started with the conversion of 15 into the corresponding benzyl ether 17 using a one-pot ${ }^{55,56}$ reduction/alkylation sequence (Scheme 3 ). To this end, reduction of (+)-sclareolide with $\mathrm{LiAlH}_{4}$ in THF at $0{ }^{\circ} \mathrm{C}^{57}$ was followed by treatment with Rochelle salt, DMF, $\mathrm{KOH}$ and 2-Me$\mathrm{C}_{6} \mathrm{H}_{4} \mathrm{CH}_{2} \mathrm{Br}$ to afford benzyl ether 17 in excellent yield. A [2,3]Wittig-type fragmentation mediated by $n$-BuLi directly yielded 


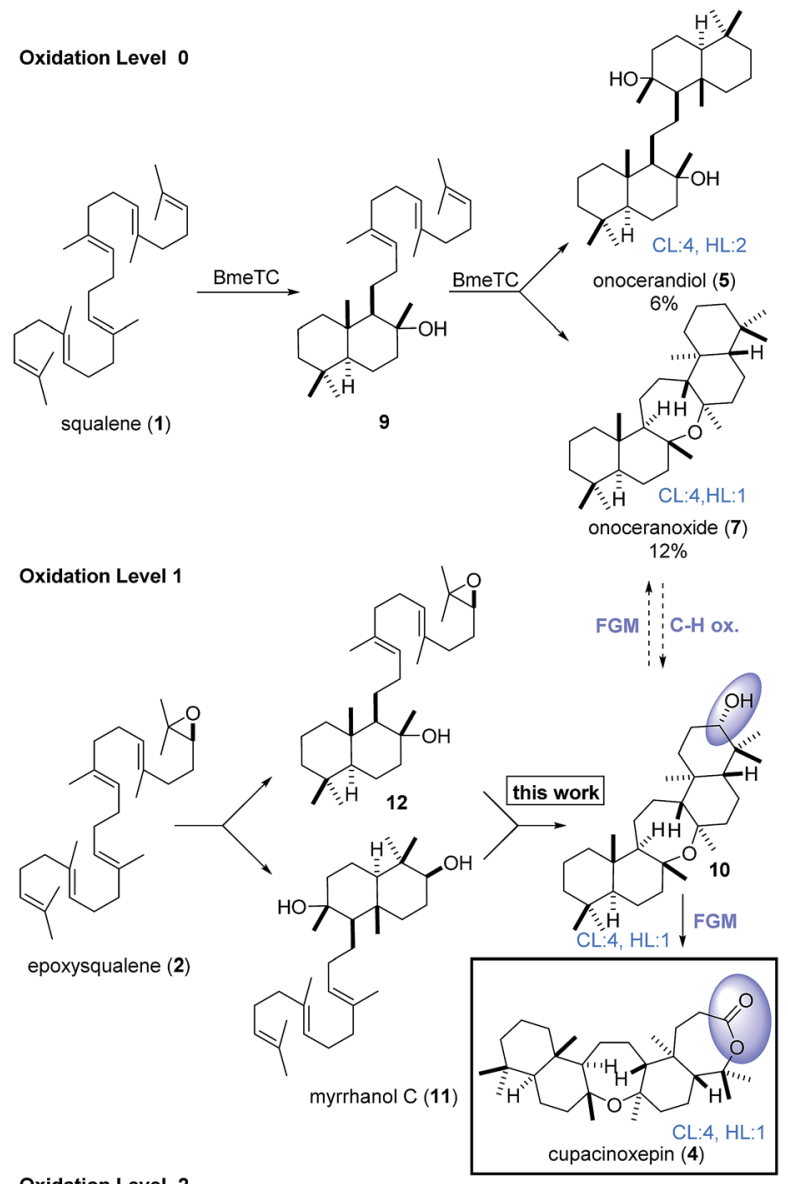

Oxidation Level 2
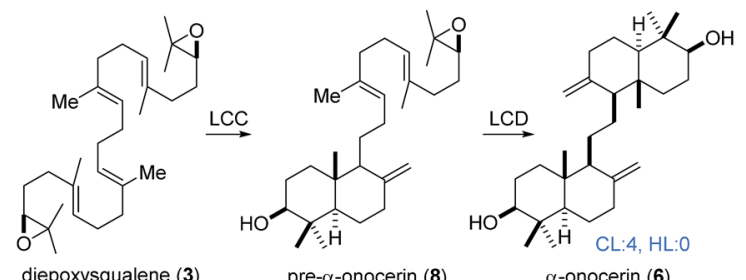

Scheme 1 Core assembly of onocerane triterpenes with regard to the oxidation level $(\mathrm{OL})$, cyclization level $(\mathrm{CL})$ and the hydration level $(\mathrm{HL})$. $\mathrm{LCC}$ and $\mathrm{LCD}=$ Lycopodium clavatum $\mathrm{C}$ and $\mathrm{D}$ respectively.

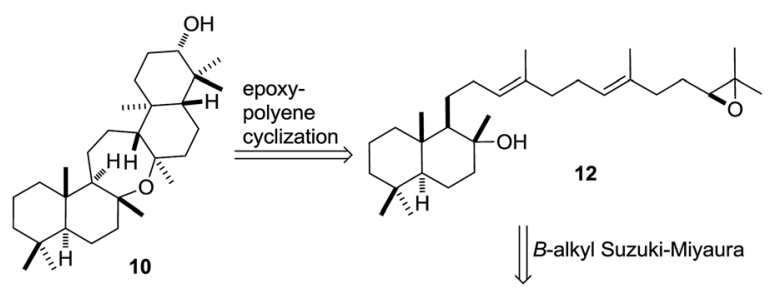<smiles>CC12CC[C@H]3C(C)(C)CCCC3(C)C1CC(=O)O2</smiles>

(+)-sclareolide (15)

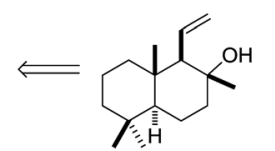

13

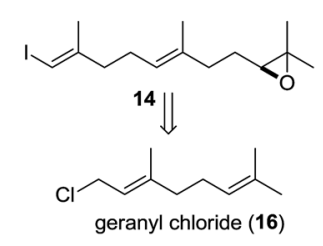

Scheme 2 Retrosynthetic analysis of 10 based on an epoxypolyene cyclization of precursor 12 .

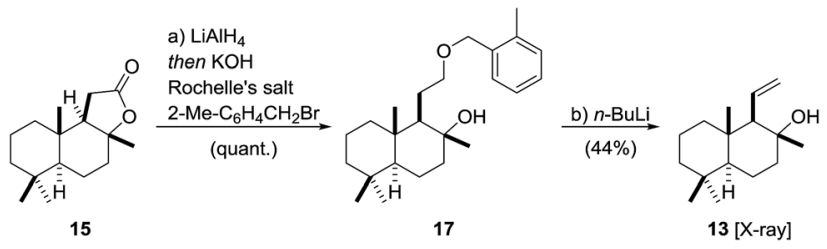

Scheme 3 Synthesis of fragment 13. Reagents and conditions: (a) $\mathrm{LiAlH}_{4}$ (0.7 eq.), THF, $0{ }^{\circ} \mathrm{C}, 40 \mathrm{~min}$ then $2-\mathrm{Me}-\mathrm{C}_{6} \mathrm{H}_{4} \mathrm{CH}_{2} \mathrm{Br}$ (2.1 eq.), $\mathrm{KOH}$ (4.0 eq.), Rochelle's salt (1.2 eq.), DMF, $45^{\circ} \mathrm{C}, 27 \mathrm{~h}$, quant.; (b) $n$-BuLi (4.0 eq.), THF, $-78{ }^{\circ} \mathrm{C}, 10 \mathrm{~min}$ to $-13{ }^{\circ} \mathrm{C}, 90 \mathrm{~min}, 44 \%$ (over 2 steps).

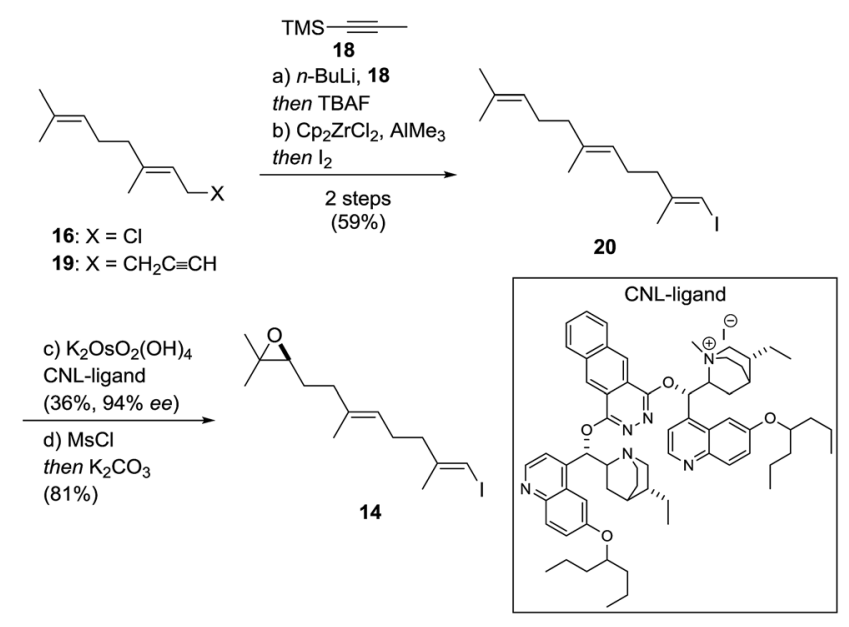

Scheme 4 Synthesis of fragment 14. Reagents and conditions: (a) $n$-BuLi (1.2 eq.), 18 (1.2 eq.), THF, $-78{ }^{\circ} \mathrm{C}, 2.5 \mathrm{~h}$ then $\operatorname{TBAF}(1.3$ eq.), $-78^{\circ} \mathrm{C}$ to $23^{\circ} \mathrm{C}, 24 \mathrm{~h}, 82 \%$; (b) $\mathrm{Cp}_{2} \mathrm{ZrCl}_{2}$ (0.25 eq.), $\mathrm{AlMe}_{3}$ (3.0 eq.), $\mathrm{H}_{2} \mathrm{O}$ (1.0 eq.), $\mathrm{CH}_{2} \mathrm{Cl}_{2},-23{ }^{\circ} \mathrm{C}, 1 \mathrm{~h}$ then $\mathrm{I}_{2}\left(1.2 \mathrm{eq}\right.$.), $\mathrm{THF},-23^{\circ} \mathrm{C}$ to $23^{\circ} \mathrm{C}$, $16 \mathrm{~h}, 72 \%$; (c) $\mathrm{K}_{2} \mathrm{OsO}_{2}(\mathrm{OH})_{4}(0.3 \mathrm{~mol} \%), \mathrm{CNL}$-ligand $(0.2 \mathrm{~mol} \%)$, $\mathrm{K}_{3} \mathrm{Fe}(\mathrm{CN})_{6}$ (3.0 eq.), $\mathrm{MeSO}_{2} \mathrm{NH}_{2}\left(1.0\right.$ eq.), $\mathrm{K}_{2} \mathrm{CO}_{3}$ (3.0 eq.), $t-\mathrm{BuOH}, \mathrm{H}_{2} \mathrm{O}$, $1{ }^{\circ} \mathrm{C}, 53 \mathrm{~h}, 36 \%, 94 \%$ ee, and $49 \%$ of 20 ; (d) $\mathrm{MsCl}$ (1.1 eq.), pyridine (15 eq.), $\mathrm{CH}_{2} \mathrm{Cl}_{2}, \mathrm{O}^{\circ} \mathrm{C}$ to $23^{\circ} \mathrm{C}, 18 \mathrm{~h}$ then $\mathrm{K}_{2} \mathrm{CO}_{3}$ (10 eq.), $\mathrm{MeOH}, 2.5 \mathrm{~h}, 81 \%$.

fragment 13 in an acceptable yield of $44 \%$ over two steps. ${ }^{58,59}$ The subtle deviation of the ether group from the literatureknown benzyl ether to its 2-Me-benzyl derivative increased the yield from $21 \%$ to $44 \%$. A screening of different ether derivatives showed alkyl substituents with benzylic hydrogen atoms in the 2-position of the aromatic ring to give higher yields of $\mathbf{1 3}$. Moreover, we observed a temperature dependence of the fragmentation yield, maximizing at $-13{ }^{\circ} \mathrm{C} .{ }^{46}$ The configuration of 13 was confirmed by X-ray crystallography. ${ }^{60}$

Vinyl iodide $\mathbf{1 4}$ was prepared from geranyl chloride via nucleophilic substitution with lithiated $\mathbf{1 8}^{\mathbf{6 1}}$ followed by desilylation with TBAF (Scheme 4). Negishi's zirconium-catalyzed carboalumination ${ }^{62,63}$ of 19 with $\mathrm{AlMe}_{3}$ and subsequent trapping of the vinyl aluminium intermediate with iodine afforded vinyl iodide 20.64,65 Dihydroxylation of the dimethyl-substituted alkene with the (DHQD) ${ }_{2}$ PHAL ligand ${ }^{66}$ (33\% yield, 97\% ee) proceeded with low position-selectivity which is reflected by the small amount of recovered starting material (25\%). Using the Corey-Noe-Lin (CNL) ligand ${ }^{67}$ increased the position-selectivity to give the terminal diol in $36 \%$ yield ( $94 \%$ ee) with $49 \%$ of 

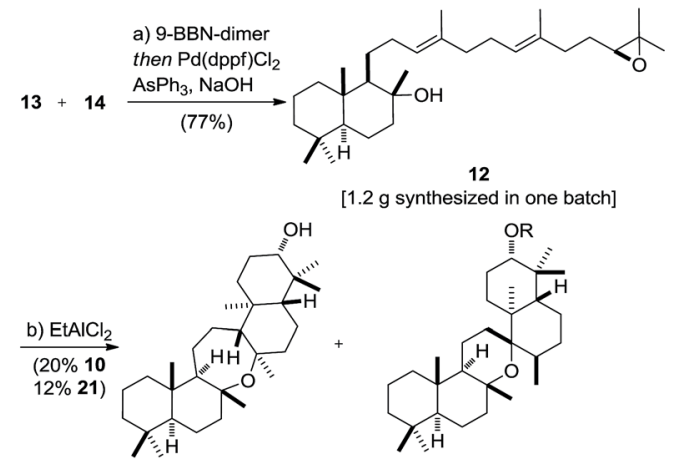

10 [X-ray $]$

c) $21 \mathrm{R}=\mathrm{H}$

[X-ray]
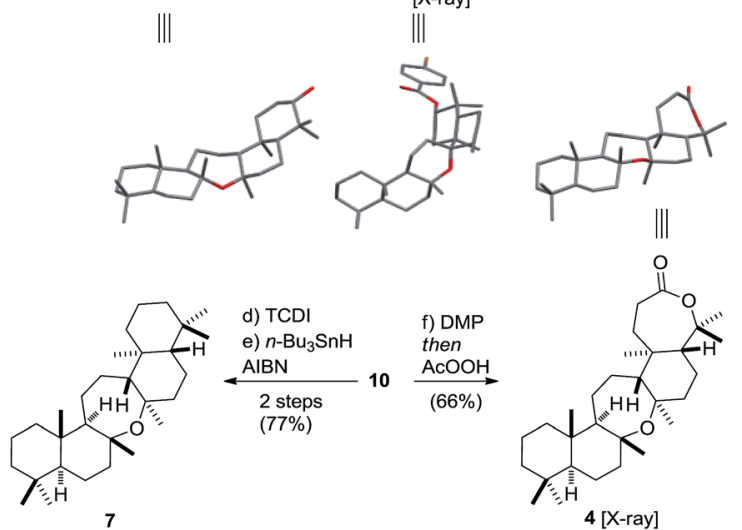

Scheme 5 Synthesis of cupacinoxepin 4 and onoceranoxide 7. Reagents and conditions: (a) 13 (1.4 eq.), 9-BBN dimer (2.8 eq.), $85^{\circ} \mathrm{C}$, $4 \mathrm{~h}$ then 14 (1.0 eq.), $\mathrm{Pd}(\mathrm{dppf}) \mathrm{Cl}_{2}$ (0.1 eq.), $\mathrm{AsPh}_{3}$ (0.4 eq.), $\mathrm{NaOH}$ (6.0 eq.), $1{ }^{\circ} \mathrm{C}, 17 \mathrm{~h}, 77 \%$; (b) $\mathrm{EtAlCl}_{2}$ (3.0 eq.), $\mathrm{CH}_{2} \mathrm{Cl}_{2}(1 \mathrm{mM}),-78{ }^{\circ} \mathrm{C}$, $1.5 \mathrm{~h}, 20 \% 10,12 \%$ 21; (c) $4-\mathrm{BrC}_{6} \mathrm{H}_{4} \mathrm{COCl}$ (5.0 eq.), 4-DMAP (20 eq.), $50{ }^{\circ} \mathrm{C}, \mathrm{CH}_{2} \mathrm{Cl}_{2}, 3$ d, 73\%; (d) TCDI (20 eq.), 4-DMAP (20 eq.), $\mathrm{CH}_{2} \mathrm{Cl}_{2}$, $70{ }^{\circ} \mathrm{C} 13.5 \mathrm{~h}, 83 \%$; (e) $n-\mathrm{Bu}_{3} \mathrm{SnH}$ (3.0 eq.), AlBN (cat.), toluene, $160{ }^{\circ} \mathrm{C}$, $10 \mathrm{~min}$ to $120^{\circ} \mathrm{C}, 20 \mathrm{~min}$ then $n-\mathrm{Bu}_{3} \mathrm{SnH}$ (3.0 eq.), AlBN (cat.), $160^{\circ} \mathrm{C}$, 10 min to $120^{\circ} \mathrm{C}, 20 \mathrm{~min}, 93 \%$; (f) $\mathrm{DMP}$ (2.0 eq.), $\mathrm{CH}_{2} \mathrm{Cl}_{2}, 23^{\circ} \mathrm{C}, 4 \mathrm{~h}$ then $\mathrm{AcOOH}$ (10 eq.), $\mathrm{NaOAc}(20$ eq.), $17 \mathrm{~h}$ then $\mathrm{AcOOH}$ (10 eq.), $\mathrm{NaOAc}(20$ eq.), $5 \mathrm{~h}, 66 \%$. DMP $=$ Dess-Martin periodinane, $\mathrm{TCDI}=1,1^{\prime}$-thiocarbonyldiimidazole, $\mathrm{AlBN}=$ azobisisobutyronitrile.

recovered alkene. ${ }^{68}$ Mesylation of the secondary alcohol and subsequent treatment with $\mathrm{K}_{2} \mathrm{CO}_{3}$ afforded epoxide 14 in $81 \%$ yield. ${ }^{69}$ With alkene 13 and vinyl iodide 14 in hand, the crucial coupling was investigated (Scheme 5). Treatment of alkene $\mathbf{1 3}$ (neat) with 9-BBN dimer at $85{ }^{\circ} \mathrm{C}$ for $4 \mathrm{~h}$ led to the expected borane, which was directly used in the $B$-alkyl Suzuki-Miyaura reaction ${ }^{69-71}$ to afford epoxy dienol 12 in $77 \%$ yield on gram scale. The stage was then set to examine the putative biomimetic tricyclization. ${ }^{72} \mathrm{We}$ anticipated the formation of the oxepane to be unfavorable both for entropic and enthalpic reasons. ${ }^{73}$ A variety of Brønsted and Lewis acids ${ }^{46}$ failed to give the desired product, but gratifyingly, treatment of 12 with EtAlCl ${ }_{2}$ at $-78{ }^{\circ} \mathrm{C}$ under high dilution $\left(\mathrm{CH}_{2} \mathrm{Cl}_{2}, 1 \mathrm{mM}\right)$ afforded a separable mixture of target compound 10 (20\%) along with another pentacyclic product $21(12 \%) \cdot{ }^{74-76}$ Spirocyclic motifs similar to $\mathbf{2 1}$ have been found in several bioactive natural products. ${ }^{77-80}$ Further conditions for the tricyclization of 9 were investigated but no product formation could be observed. ${ }^{46}$
The structures of oxepane $\mathbf{1 0}$ and $p$-Br-benzoate derivative $\mathbf{2 2}$ were confirmed by X-ray crystallography. Despite its rather low yield, the cyclization generated four stereogenic centers and the remaining carbon skeleton in a single transformation. Additionally, the secondary alcohol in $\mathbf{1 0}$ might serve as a handle in future SAR studies and enable the evaluation of this class of pentacyclic onocerane triterpenoids as potential antimalarial drug leads. ${ }^{\mathbf{8 1 , 8 2}}$ In addition, recent work in the field of $\mathrm{C}-\mathrm{H}$ functionalization has demonstrated the sclareolide scaffold to be amenable for the selective introduction of other functional groups. ${ }^{83-90}$ Next, the major cyclization product 10 was subjected to a one-pot Dess-Martin/Baeyer-Villiger oxidation ${ }^{\mathbf{9 1 - 9 4}}$ to afford cupacinoxepin in $66 \%$ yield $(1.7 \%$ overall yield starting from 16). The spectroscopic data, including the optical rotation, matched those reported in the literature, thereby determining the absolute configuration of (+)-cupacinoxepin. ${ }^{6}$ In addition, we were able to obtain a crystal suitable for the direct determination of the absolute configuration of 4 by X-ray crystallography. Onoceranoxide 7 was formed from 10 via formation of the thiocarbamate and subsequent reduction with tributyltin hydride in $77 \%$ yield ( 2 steps) (2.0\% overall yield starting from 16). ${ }^{95}$ The spectroscopic data matched those reported in the literature. ${ }^{26}$

In order to investigate the mechanism of the epoxypolyene cyclization in more detail and to get insight into the low selectivity for the desired trans-anti-trans pathway, well established density functional theory (DFT) methods were applied (mPW1PW91/6-31+G(d,p)//B3LYP/6-31+G(d)). ${ }^{46}$ Two epimeric trans-decalin-type structures ( $S$-epimer 23 and $R$-epimer 24, Scheme 6) were predicted, based on inherent reactivity preferences (i.e., in the absence of solvent or enzyme), ${ }^{\mathbf{9 6}}$ to result from epoxydiene cyclization, consistent with previous work by Corey and Shenvi on related systems. ${ }^{75,97}$ The predicted major intermediate $\mathbf{2 3}$ is derived from a chair-chair conformation, while $\mathbf{2 4}$ is derived from a chair-boat conformation. ${ }^{75,80}$

For 23, 7-membered ring formation was predicted to be preferred over other pathways by several kcal mol ${ }^{-1}$. For 24, 1,2hydride shift to form 25/6-membered ring formation was predicted to be preferred over formation of a 7-membered ring by several kcal mol${ }^{-1}$. As shown in the transition state structure for formation of $\mathbf{2 5}$, the hydride shift appears to be assisted by the tertiary hydroxyl group (via a favorable electrostatic interaction between the partially negatively charged oxygen and the partially positively charged migrating hydrogen; related interactions have been described previously). ${ }^{\mathbf{9 8}, 99}$ In addition, the biosynthetic relevance of the epoxypolyene cyclization was probed by incubation of $\mathbf{1 2}$ with BmeTC. GC-MS analysis revealed the formation of $\mathbf{1 0}$ along with an elimination product. $^{46}$ The absence of $\mathbf{2 1}$ indicates the influence of BmeTC in overriding inherent reactivity and enforcing the chair-chair conformation leading to $\mathbf{1 0 .}$

In conclusion, we have provided access to a new class of pentacyclic onocerane triterpenoids. Additionally, we have completed the first asymmetric synthesis of antiprotozoal agent (+)-cupacinoxepin and (+)-onoceranoxide and determined their absolute configuration. By using an epoxypolyene cascade tricyclization as the key step, we were able to rapidly assemble the 


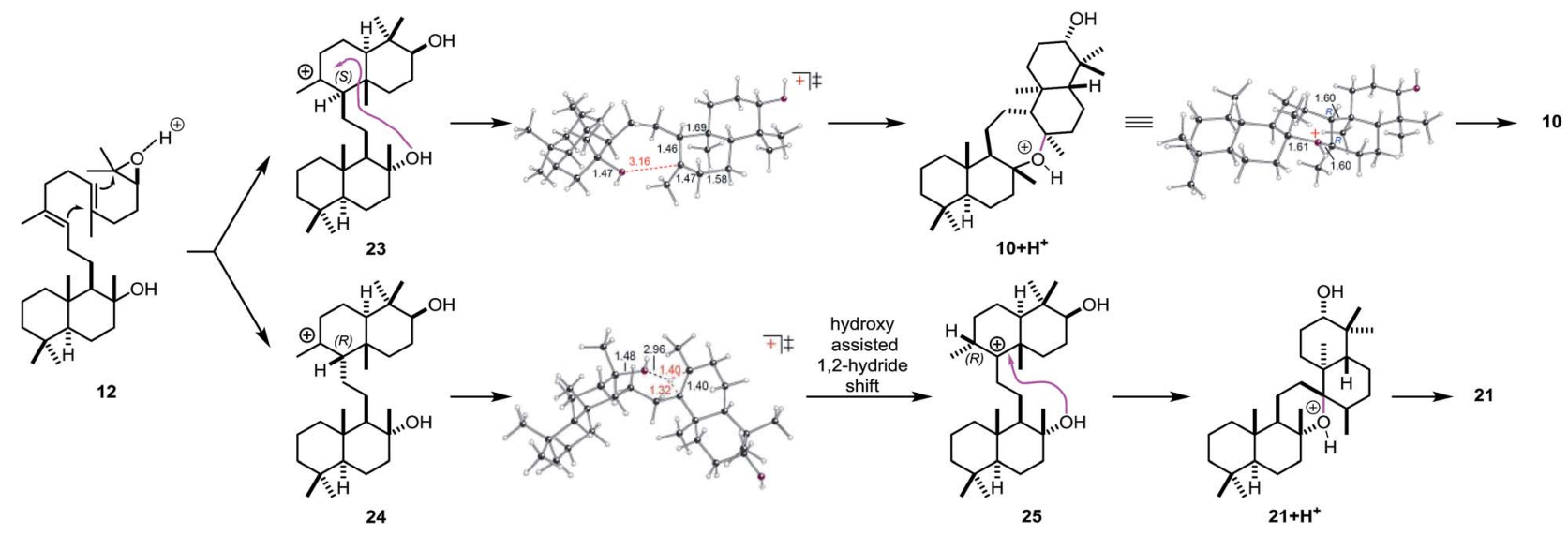

Scheme 6 Carbocation rearrangements leading to 10 and 21, modeled with $\mathrm{H}^{+}$in place of Lewis acid (LA)

fused pentacyclic structure in a single synthetic operation. The putative biosynthetic precursor was assembled from two terpene derived fragments using a $B$-alkyl Suzuki-Miyaura reaction. Our synthetic route to cupacinoxepin consists of seven steps from geranyl chloride, four of which are $\mathrm{C}-\mathrm{C}$ bond formations.

\section{Conflicts of interest}

There are no conflicts to declare.

\section{Acknowledgements}

We thank the Studienstiftung des deutschen Volkes for a doctoral fellowship (F. B.), Buchler GmbH (Braunschweig) for a generous donation of dihydrochinidin-hydrochloride, Joanna Najdek, Anna Timofeeva, Luciné V. Gabriel, Ryan Allen for experimental assistance with the [2,3]-Wittig-type fragmentation, Tobias Olbrisch for the isolation of $\alpha$-onocerin and Dr Jens Schmidt and Prof. Dr Christian B. W. Stark (Universität Hamburg) for experimental data and a generous donation of the Corey-Noe-Lin catalyst. The computational work was supported by the US National Science Foundation (CHE-1565933 and CHE-030089 [via XSEDE] to D. J. T.). This work was supported by JSPS KAKENHI Grant Numbers 25450149 and 16K14911 (to T. S.).

\section{Notes and references}

1 J. Gershenzon and N. Dudareva, Nat. Chem. Biol., 2007, 3, 408-414.

2 R. Xu, G. C. Fazio and S. P. T. Matsuda, Phytochemistry, 2004, 65, 261-291.

3 R. Thimmappa, K. Geisler, T. Louveau, P. O'Maille and A. Osbourn, Annu. Rev. Plant Biol., 2014, 65, 225-257.

4 V. Domingo, J. F. Arteaga, J. F. Quilez del Moral and A. F. Barrero, Nat. Prod. Rep., 2009, 26, 115-134.

5 B. Meunier, S. P. de Visser and S. Shaik, Chem. Rev., 2004, 104, 3947-3980.
6 M. S. Gachet, O. Kunert, M. Kaiser, R. Brun, M. Zehl, W. Keller, R. A. Muñoz, R. Bauer and W. Schuehly, J. Nat. Prod., 2011, 74, 559-566.

7 A. F. Barrero, M. M. Herrador, J. F. Quílez del Moral, P. Arteaga, J. F. Arteaga, M. Piedra and E. M. Sánchez, Org. Lett., 2005, 7, 2301-2304.

8 M. Nishizawa, H. Nishide and Y. Hayashi, Tetrahedron Lett., 1984, 25, 5071-5074.

9 R. Carman and H. Deeth, Aust. J. Chem., 1971, 24, 1099-1102.

10 E. E. van Tamelen, M. A. Schwartz, E. J. Hessler and A. Storni, Chem. Commun., 1966, 409-411.

11 P. F. Vlad, K. I. Kuchkova, A. N. Aryku and K. Deleanu, Russ. Chem. Bull., 2005, 54, 2656-2658.

12 E. Romann, A. J. Frey, P. A. Stadler and A. Eschenmoser, Helv. Chim. Acta, 1957, 40, 1900-1917.

13 E. J. Corey and R. R. Sauers, J. Am. Chem. Soc., 1957, 79, 39253926.

14 E. J. Corey and R. R. Sauers, J. Am. Chem. Soc., 1959, 81, 17391743.

15 D. H. R. Barton and K. H. Overton, J. Chem. Soc., 1955, 26392652.

16 Y. Mi, J. V. Schreiber and E. J. Corey, J. Am. Chem. Soc., 2002, 124, 11290-11291.

17 Y. Tsuda, N. Kashiwaba, M. Kajitani and J. Yasui, Chem. Pharm. Bull., 1981, 29, 3424-3426.

18 G. Stork, A. Meisels and J. E. Davies, J. Am. Chem. Soc., 1963, 85, 3419-3425.

19 N. Danieli, Y. Mazur and F. Sondheimer, Tetrahedron, 1967, 23, 509-514.

20 J. Kokosi and C. Schmidt, Synth. Commun., 1985, 15, 341-354.

21 R. F. Church, R. E. Ireland and J. A. Marshall, Tetrahedron Lett., 1961, 2, 34-38.

22 S. Berger and D. Sicker, Classics in Spectroscopy: Isolation and Structure Elucidation of Natural Products, Wiley-VCH, Weinheim, 2009.

23 D. Ueda, T. Hoshino and T. Sato, J. Am. Chem. Soc., 2013, 135, 18335-18338.

24 M. G. Rowan, P. D. G. Dean and T. W. Goodwin, FEBS Lett., 1971, 12, 229-232. 
25 T. Araki, Y. Saga, M. Marugami, J. Otaka, H. Araya, K. Saito, M. Yamazaki, H. Suzuki and T. Kushiro, ChemBioChem, 2016, 17, 288-290.

26 H. Ageta, K. Shiojima and K. Masuda, Chem. Pharm. Bull., 1982, 30, 2272-2274.

27 Y. Arai, M. Yamaide, S. Yamazaki and H. Ageta, Phytochemistry, 1991, 30, 3369-3377.

28 A. S. Kleinke, D. Webb and T. F. Jamison, Tetrahedron, 2012, 68, 6999-7018.

29 H. Bouanou, J. A. Gil, R. Alvarez-Manzaneda, R. Chahboun and E. Alvarez-Manzaneda, J. Org. Chem., 2016, 81, 1000210008.

30 M. T. Corbett and J. S. Johnson, Chem. Sci., 2013, 4, 28282832.

31 E. J. Alvarez-Manzaneda, R. Chaboun, E. Alvarez, E. Cabrera, R. Alvarez-Manzaneda, A. Haidour and J. M. Ramos, Synlett, 2006, 2006, 1829-1834.

32 M. Maemoto, A. Kimishima and T. Nakata, Org. Lett., 2009, 11, 4814-4817.

33 H. Shigehisa, M. Hayashi, H. Ohkawa, T. Suzuki, H. Okayasu, M. Mukai, A. Yamazaki, R. Kawai, H. Kikuchi, Y. Satoh, A. Fukuyama and K. Hiroya, J. Am. Chem. Soc., 2016, 138, 10597-10604.

34 S. Pan, J. Xuan, B. Gao, A. Zhu and H. Ding, Angew. Chem., Int. Ed., 2015, 54, 6905-6908.

35 L. Catti and K. Tiefenbacher, Chem. Commun., 2015, 51, 892894.

36 G. A. Olah, A. P. Fung and R. Malhotra, Synthesis, 1981, 1981, 474-476.

37 L. Fang, Y. Chen, J. Huang, L. Liu, J. Quan, C.-c. Li and Z. Yang, J. Org. Chem., 2011, 76, 2479-2487.

38 O. Piva, in Synthesis of Saturated Oxygenated Heterocycles II: 7to 16-Membered Rings, ed. J. Cossy, Springer Berlin Heidelberg, Berlin, Heidelberg, 2014, pp. 283-320, DOI: 10.1007/978-3-642-41470-1_1.

39 R. B. Boar, L. A. Couchman, A. J. Jaques and M. J. Perkins, J. Am. Chem. Soc., 1984, 106, 2476-2477.

40 R. A. Yoder and J. N. Johnston, Chem. Rev., 2005, 105, 47304756.

41 L. F. Tietze, G. Brasche and K. M. Gericke, Domino Reactions in Organic Synthesis, Wiley-VCH, Weinheim, 2006.

42 S. A. Snyder and A. M. Levinson, in Comprehensive Organic Synthesis II, ed. P. Knochel and G. A. Molander, Elsevier, Amsterdam, 2nd edn, 2014, p. 268, DOI: 10.1016/B978-008-097742-3.00309-8.

43 M. Baunach, J. Franke and C. Hertweck, Angew. Chem., Int. Ed., 2015, 54, 2604-2626.

44 V. K. Aggarwal, P. A. Bethel and R. Giles, J. Chem. Soc., Perkin Trans. 1, 1999, 3315-3321.

45 T. N. Barrett and A. G. M. Barrett, J. Am. Chem. Soc., 2014, 136, 17013-17015.

46 See ESI $\dagger$ for details.

47 S. Nakamura, K. Ishihara and H. Yamamoto, J. Am. Chem. Soc., 2000, 122, 8131-8140.

48 M. Uyanik, H. Ishibashi, K. Ishihara and H. Yamamoto, Org. Lett., 2005, 7, 1601-1604.
49 T. Abe and T. Hoshino, Org. Biomol. Chem., 2005, 3, 31273139.

50 D. Urabe, T. Asaba and M. Inoue, Chem. Rev., 2015, 115, 9207-9231.

51 J. Mulzer, Nat. Prod. Rep., 2014, 31, 595-603.

52 Z. G. Brill, M. L. Condakes, C. P. Ting and T. J. Maimone, Chem. Rev., 2017, 117, 11753-11795.

53 T. Newhouse, P. S. Baran and R. W. Hoffmann, Chem. Soc. Rev., 2009, 38, 3010-3021.

54 For an attempted synthesis, see: J. H. George, M. McArdle, J. E. Baldwin and R. M. Adlington, Tetrahedron, 2010, 66, 6321-6330.

55 C. Vaxelaire, P. Winter and M. Christmann, Angew. Chem., Int. Ed., 2011, 50, 3605-3607.

56 Y. Hayashi, Chem. Sci., 2016, 7, 866-880.

57 K. K. W. Kuan, H. P. Pepper, W. M. Bloch and J. H. George, Org. Lett., 2012, 14, 4710-4713.

58 M. Matsushita, Y. Nagaoka, H. Hioki, Y. Fukuyama and M. Kodama, Chem. Lett., 1996, 25, 1039-1040.

59 Direct conversion of the primary alcohol into a leaving group and subsequent elimination was outcompeted by intramolecular substitution forming ambroxide.

60 CCDC 1529115 (13), 1529116 (4), 1529117 (22), 1529118 (10) contain the supplementary crystallographic data for this paper. $\dagger$

61 E. J. Corey and H. A. Kirst, Tetrahedron Lett., 1968, 9, 50415043.

62 T. Yoshida and E. Negishi, J. Am. Chem. Soc., 1981, 103, 4985-4987.

63 P. Wipf and S. Lim, Angew. Chem., Int. Ed. Engl., 1993, 32, 1068-1071.

64 D. J. Clausen, S. Wan and P. E. Floreancig, Angew. Chem., Int. Ed., 2011, 50, 5178-5181.

65 V. Domingo, L. Lorenzo, J. F. Quilez del Moral and A. F. Barrero, Org. Biomol. Chem., 2013, 11, 559-562.

66 H. C. Kolb, M. S. VanNieuwenhze and K. B. Sharpless, Chem. Rev., 1994, 94, 2483-2547.

67 (a) E. J. Corey, M. C. Noe and S. Lin, Tetrahedron Lett., 1995, 36, 8741-8744; (b) J. Schmidt and C. B. W. Stark, Org. Lett., 2012, 14, 4042-4045.

68 Determination of the absolute configuration by Mosher ester analysis.

69 K. Surendra and E. J. Corey, J. Am. Chem. Soc., 2008, 130, 8865-8869.

70 V. Domingo, L. Silva, H. R. Diéguez, J. F. Arteaga, J. F. Quílez del Moral and A. F. Barrero, J. Org. Chem., 2009, 74, 61516156.

71 D. T. Hog, F. M. E. Huber, G. Jiménez-Osés, P. Mayer, K. N. Houk and D. Trauner, Chem.-Eur. J., 2015, 21, 1364613665.

72 M. Razzak and J. K. De Brabander, Nat. Chem. Biol., 2011, 7, 865-875.

73 C. Galli and L. Mandolini, Eur. J. Org. Chem., 2000, 31173125.

74 S. V. Pronin and R. A. Shenvi, Nat. Chem., 2012, 4, 915-920. 75 R. A. Shenvi and E. J. Corey, Org. Lett., 2010, 12, 3548-3551. 
76 E. J. Corey and M. Sodeoka, Tetrahedron Lett., 1991, 32, 70057008.

77 W. H. Gerwick and W. Fenical, J. Org. Chem., 1981, 46, 22-27.

78 A. Abad, C. Agulló, M. Arnó, A. C. Cuñat, B. Meseguer and R. J. Zaragozá, J. Org. Chem., 1998, 63, 5100-5106.

79 A. Grube, M. Assmann, E. Lichte, F. Sasse, J. R. Pawlik and M. Köck, J. Nat. Prod., 2007, 70, 504-509.

80 A. W. Markwell-Heys and J. H. George, Org. Biomol. Chem., 2016, 14, 5546-5549.

81 B. T. Grimberg and R. K. Mehlotra, Pharmaceuticals, 2011, 4, 681.

82 E. L. Flannery, A. K. Chatterjee and E. A. Winzeler, Nat. Rev. Microbiol., 2013, 11, 849-862.

83 C. R. Shugrue and S. J. Miller, Chem. Rev., 2017, 117, 1189411951.

84 R. K. Quinn, Z. A. Könst, S. E. Michalak, Y. Schmidt, A. R. Szklarski, A. R. Flores, S. Nam, D. A. Horne, C. D. Vanderwal and E. J. Alexanian, J. Am. Chem. Soc., 2016, 138, 696-702.

85 M. S. Chen and M. C. White, Science, 2010, 327, 566-571.

86 Y. Kawamata, M. Yan, Z. Liu, D.-H. Bao, J. Chen, J. T. Starr and P. S. Baran, J. Am. Chem. Soc., 2017, 139, 7448-7451.
87 W. Liu, X. Huang, M.-J. Cheng, R. J. Nielsen, W. A. Goddard and J. T. Groves, Science, 2012, 337, 1322-1325.

88 K. Chen, A. Eschenmoser and P. S. Baran, Angew. Chem., Int. Ed., 2009, 48, 9705-9708.

89 V. A. Schmidt, R. K. Quinn, A. T. Brusoe and E. J. Alexanian, J. Am. Chem. Soc., 2014, 136, 14389-14392.

90 O. F. Jeker, A. G. Kravina and E. M. Carreira, Angew. Chem., Int. Ed., 2013, 52, 12166-12169.

91 D. B. Dess and J. C. Martin, J. Org. Chem., 1983, 48, 41554156.

92 A. Baeyer and V. Villiger, Ber. Dtsch. Chem. Ges., 1899, 32, 3625-3633.

93 R. R. Sauers, J. Am. Chem. Soc., 1959, 81, 925-927.

94 J. Meinwald and E. Frauenglass, J. Am. Chem. Soc., 1960, 82, 5235-5239.

95 M. Göhl and K. Seifert, Eur. J. Org. Chem., 2014, 6975-6982. 96 D. J. Tantillo, Angew. Chem., Int. Ed., 2017, 56, 10040-10045. 97 E. J. Corey and B. E. Roberts, Tetrahedron Lett., 1997, 38, 8921-8924.

98 M. W. Lodewyk, D. Willenbring and D. J. Tantillo, Org. Biomol. Chem., 2014, 12, 887-894.

99 S. R. Hare, R. P. Pemberton and D. J. Tantillo, J. Am. Chem. Soc., 2017, 139, 7485-7493. 